\title{
UTILIDAD DE MARCADORES RAPD EN LA CARACTERIZACIÓN MOLECULAR DE QUEQUISQUE (Xanthosoma spp.) DE NICARAGUA. ESTUDIO PRELIMINAR
}

\section{Guillermo Reyes-Castro}

PhD. Agronomía, Facultad de Agronomía, Universidad Nacional Agraria, km 12 1⁄2 carretera norte, Managua. Email: Guillermo.Reyes. Castro@una.edu.ni Tel: (505) 2233-1845
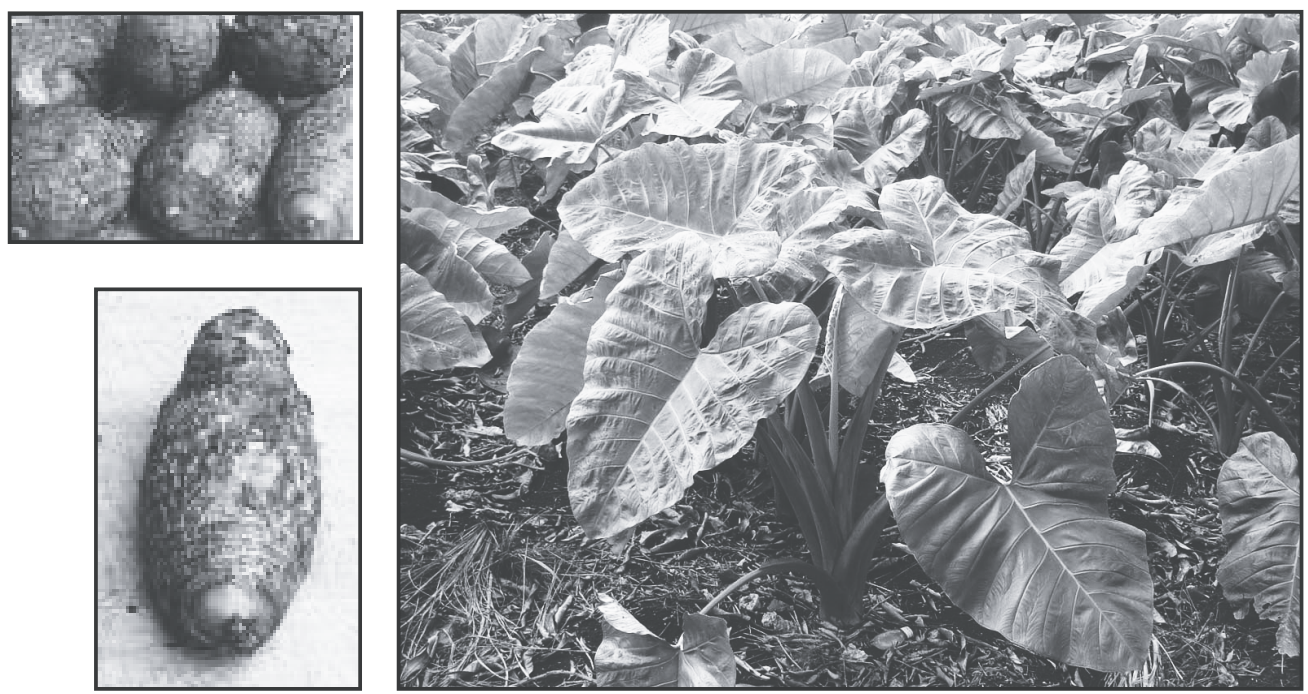

\section{RESUMEN}

El quequisque es un cultivo de importancia en los trópicos y subtrópicos por ser fuente de alimento y recursos para productores. Nicaragua está ubicada en el centro de origen del género Xanthosoma, donde pueden encontrarse muchas especies silvestres de uso potencial. Sin embargo, la información sobre la relación genética inter e intra específica es escasa. Se evaluó el uso de los marcadores moleculares generados por 40 cebadores RAPD (kits B y D, Operon technologies) en la caracterización de especies del género Xanthosoma colectados en Nicaragua. Con tal fin se extrajo ADN de vitroplantas de tres especies Xanthosoma silvestres y cuatro cultivadas, cuatro Alocasia ornamentales y tres Colocasia cultivadas. Los marcadores moleculares generados fueron sometidos al análisis fenético utilizando el programa Neighbour joining. Catorce de los cebadores revelaron polimorfismo entre los genotipos. El dendograma generado agrupó las Xanthosoma cultivadas y silvestres, exceptuando $X$ mexicum. Las especies Colocasia y Alocasia no formaron un grupo claro. Este estudio confirma la variación genética en las especies Xanthosoma silvestres y cultivadas creciendo en Nicaragua. Los marcadores moleculares generados por los catorce cebadores RAPD pueden ser utilizados para la caracterización molecular del banco de germoplasma del género Xanthosoma colectado en el país.

Palabras clave: Xanthosoma, marcadores moleculares, diversidad genética, RADS

Abreviaturas: RAPD, técnica del ADN polimórfico amplificado al azar.

\begin{abstract}
Cocoyam is an important crop located in tropic and sub-tropic because it provides food and incomes to peasant. Nicaragua is in the centre of origin of Xanthosoma genus where wild species with potential use can be found. Nevertheless, the information about the genetic relationship among and within genera is scarce. The use of molecular markers generated from 40 RAPD primers (B and D kits Operon technologies) in the characterization of Xanthosoma species grown in Nicaragua was evaluated. With this purpose DNA from four cultivated and three wild Xanthosoma, four ornamental Alocasia, and three cultivated Colocasia genotypes was extracted. The generated molecular markers were submitted to phenetic analysis using the Neighbour joining program. Fourteen of all the primers revealed polymorphism between the genotypes. Dendrogram generated grouped the cultivated and wild Xanthosoma together excepting $X$. mexicanum. The Colocasia and Alocasia species did not form any clear group. This study confirms the genetic the variation in wild and cultivated Xanthosoma family grown in Nicaragua. The polymorphic molecular markers generated for the 14 RAPD primers can be used for the molecular characterization of the Xanthosoma germplasm collected in Nicaragua.

Key words: Genetic diversity, RAPD markers, Xanthosoma
\end{abstract}




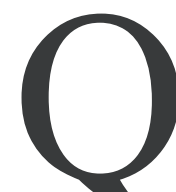

uequisque (Xanthosoma spp.), la segunda Araceae comestible más importante en el mundo (Bown, 2000), suministra carbohidratos, proteínas, grasas y vitaminas (Tambong en L, 1997; Mayo et al., 1997) y recursos a los productores (Tambong et al., 1997).

El género Xanthosoma pertenece a la tribu Caladieae, y es originario de América Tropical y Subtropical, donde se distribuyen 57 especies (Mayo et al., 1997; Bown, 2000). En Nicaragua, ubicada en el centro de origen de Xanthosoma, el quequisque se cultiva a nivel nacional y es la segunda raíz y tubérculo en áreas de producción (Reyes et al,. 2009). En la producción nacional se emplean relativamente pocos cultivares, ninguno de ellos resistente a las principales plagas y enfermedades que causan drásticas reducciones en la producción.

Debido a las afectaciones por el Dasheen Mosaic Virus (DsMV), Pythium myriotylum, (mal seco) y los cambios climáticos, la producción quequisquera nacional ha disminuido significativamente en los últimos años, por lo que urge iniciar trabajos de mejora genética en búsqueda de cultivares resistentes. Una importante acción orientada a encontrar genes de resistencia ha sido la colecta y el establecimiento del banco de germoplasma de la especies Xanthosoma realizada por García (2007). Dicho banco está conformado por 61 accesiones de 6 especies (Xanthosoma violaceum, X. sagittifolium, $X$. atrovirens, $X$. mexicanum, $X$. wendlandii y $X$. robustum). Veintitrés de las accesiones son cultivadas comestibles y 22 son parientes silvestres cercanas de las cultivadas. Todas las accesiones han sido caracterizadas morfológicamente, sin embargo, se requiere la caracterización molecular para complementar los estudios de premejora.

Hasta hace pocos años la información generada en términos de la diversidad genética del género Xanthosoma era escasa. En la actualidad las técnicas moleculares han permitido el incremento en el número de estudios de diversidad genética en Xanthosoma y géneros relacionados. La técnica del ADN polimórfico amplificado al azar (RAPD, por sus siglas en inglés) ha generado información valiosa en estudios de diversidad genética y parentesco entre especies. La evaluación de la diversidad genética del género Xanthosoma en Nicaragua utilizando marcadores moleculares podría revelar la relación genética entre especies cultivadas y silvestres a nivel intra e interespecífica y entre el género Xanthosoma y otros géneros dentro de la familia de las Aráceaes. Lo anterior es de gran valor práctico para propósitos de conservación, propagación y mejora genética del quequisque.

Considerando la necesidad de ampliar el conocimiento de la diversidad genética del quequisque para los fines prácticos antes mencionados, se llevó a cabo el presente estudio cuyo objetivo fue evaluar la utilidad de marcadores moleculares generados por 40 cebadores RAPD en el estudio de la diversidad genética de varias especies del género Xanthosoma. La información generada servirá para la caracterización molecular del banco de germoplasma del género Xanthosoma colectado en Nicaragua.

\section{MATERIALES Y MÉTODOS}

Material vegetal. Se colectaron cormos y cormelos de plantas de tres especies silvestres y cuatro cultivadas del género Xanthosoma, cuatro especies ornamentales de Alocasia y tres especies cultivadas de Colocasia. Todo el material vegetal antes descrito se colectó en diferentes zonas de Nicaragua (tabla 2). Yemas aisladas de cormos y cormelos se establecieron in vitro en el laboratorio de cultivo de tejidos de la Universidad Nacional Agraria (UNA). Las plantas fueron trasladadas en tubos de ensayo al Departamento de Biología de Plantas y Genética Forestal de la Universidad de Ciencias Agrícolas de Suecia (SLU, por sus siglas en sueco). Se colectaron muestras de las hojas jóvenes por genotipo y se les extrajo el ADN genómico con el kit de extracción de ADN DNeasy ${ }^{\mathrm{TM}}$ Plant Minikit. El $\mathrm{ADN}$ de las muestras fue mantenido a $-20^{\circ} \mathrm{C}$.

Reacción PCR. Se evaluaron 40 cebadores de los kits Operon B y D (Operon Technologies, Alameda, CA). La reacción de amplificación se realizó siguiendo las recomendaciones de Williams et al., (1990). La mezcla de la reacción PCR consistió en $2.5 \mu 1$ de $10 \mathrm{X}$ buffer $\sin \mathrm{MgCl}_{2}$ (100 mM Tris- $\mathrm{HCl}, 500 \mathrm{mM} \mathrm{KCl}, \mathrm{pH} 8.3$ a $\left.20{ }^{\circ} \mathrm{C}\right) ; 2.4 \mu 1$ de $\mathrm{MgCl}_{2}(2.5 \mathrm{mM}) ; 1 \mu 1$ de solución de nucleótidos (100 mM de dATP, dCTP, dGTP y dTTP); 0.5 $\mu 1$ de Taq ADN polimerasa (Fermentas ${ }^{\mathrm{TM}} 500$ unidades); $15.1 \mu 1$ de agua bidestilada-desionizada estéril, $2.0 \mu 1$ de cebador específico y $1.5 \mu \mathrm{l}$ de la muestra de ADN.

Amplificación PCR. La amplificación del ADN se realizó en un termociclador PCR Express Thermal Cycler (Hybaid) el cual se programó para el precalentamiento por tres minutos a $94{ }^{\circ} \mathrm{C}$, seguido de 40 ciclos de 35 segundos a $95{ }^{\circ} \mathrm{C}, 35$ segundos a $35^{\circ} \mathrm{C}$, y 1.2 minutos a $72{ }^{\circ} \mathrm{C}$, y finalmente el paso de elongación por 10 minutos a $72^{\circ} \mathrm{C}$.

Aproximadamente $15 \mu 1$ de los productos PCR amplificados se depositaron en un gel de sacarosa $(0.8 \%)$ y separados por electroforesis en un búfer de $0.5 \mathrm{X}$ TrisBorate EDTA a $5 \mathrm{~V} \mathrm{~cm}^{-1}$. Los geles fueron teñidos con bromuro de etidio y los productos PCR visualizados con luz ultravioleta, y fotografiados con una cámara Gel Doc 2000 camara (BIO-RAD). Un marcador molecular Ladder de 100 pares de bases fue incluido en todos los 
geles como indicador del peso molecular aproximado de las bandas.

Análisis de los datos RAPD. Con el objetivo de contabilizar las bandas reproducibles e inequívocas, todas las muestras de ADN se amplificaron dos veces con el mismo cebador en rondas PCR independientes. Las bandas registradas que diferían entre dos o más individuos eran consideradas ADN polimórficas y fueron utilizadas como marcadores genéticos. La presencia o ausencia de productos amplificados se registraron utilizando el sistema binario de 1 = banda presente y $2=$ banda ausente. $\mathrm{La}$ matriz de doble entrada generada (bandas por genotipos) fue utilizada para calcular el coeficiente de similitud de Jaccard con el programa SIMQUAL. Posteriormente mediante el análisis de agrupamiento, utilizando la técnica de ligamiento promedio no ponderado UPGMA (por sus siglas en inglés), se obtuvo un gráfico de la relación genética entre los genotipos en estudio.

\section{RESULTADOS Y DISCUSIÓN}

Catorce de los 40 cebadores evaluados (35\%), fueron altamente informativos, generaron desde una (OPD-15) hasta 20 bandas (OPD-3) con rangos de tamaño de 0.25 a $3 \mathrm{~kb}$ (tabla 1). En total se obtuvieron 173 bandas. Los cebadores de las series D: 03, 05, 07, 08, 11, 13, 18, 19 y 20; y el cebador B-20 produjeron de 10 a 20 bandas. Estos cebadores pueden ser utilizados para diferenciar las especies Xanthosoma de otros géneros. a
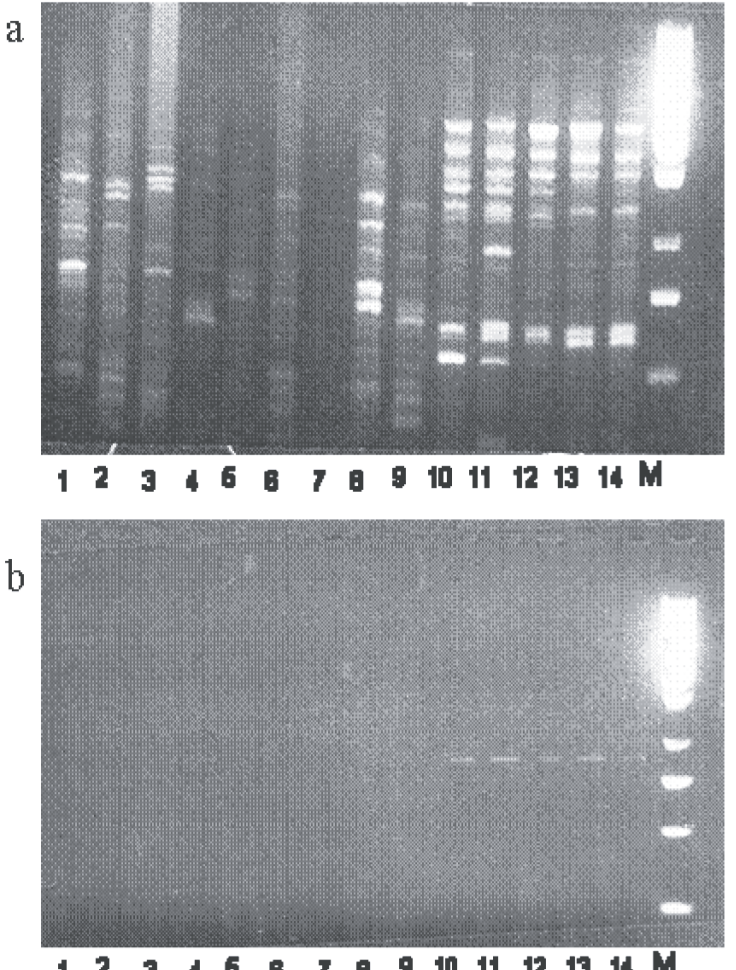

7.- Al-ce

8. Al-CB

9.- $\mathrm{Al}-\mathrm{C} A$

10. $\mathrm{Xa}-\mathrm{S} 2$

11.- My-C

12. $-\mathrm{NG}-\mathrm{C}$

13.- Apd-C

14.- $\mathrm{Bco}-\mathrm{C}$

$123 / 687891011$ 12 13 $14 \mathrm{M}$

Tabla 1. Cebadores más informativos.

\begin{tabular}{lcccl}
\hline Cebadores & $\begin{array}{l}\text { Bandas } \\
\text { generadas }\end{array}$ & $\begin{array}{l}\text { Rango de bandas } \\
\text { por genotipo }\end{array}$ & $\begin{array}{l}\text { Promedio de bandas } \\
\text { por genotipo }\end{array}$ & $\begin{array}{l}\text { Secuencia de } \\
\text { nucleótidos }\end{array}$ \\
\hline OPB-1 & 7 & $1-7$ & 3.3 & GTTTCGCTCC \\
OPB-11 & 8 & $0-8$ & 3.5 & GTAGACCCTT \\
OPB-20 & 10 & $0-7$ & 9.1 & GGACCCTTAC \\
OPD-3 & 20 & $2-10$ & 6.1 & GTCGCCGTCA \\
OPD-5 & 11 & $3-10$ & 5.7 & TGAGCGGACA \\
OPD-7 & 12 & $0-8$ & 3.6 & TTGGCACGGG \\
OPD-8 & 14 & $0-9$ & 4.3 & GTGTGCCCCA \\
OPD-11 & 19 & $2-11$ & 6.6 & AGCGCCATTG \\
OPD-13 & 17 & $0-4$ & 8.3 & GGGGTGACGA \\
OPD-15 & 1 & $0-1$ & 0.4 & CATCCGTGCT \\
OPD-17 & 8 & $0-4$ & 2.4 & TTTCCCACGG \\
OPD-18 & 13 & $2-8$ & 4.3 & GAGAGCCAAC \\
OPD-19 & 16 & $0-11$ & 3.9 & ACCCGGTCAC \\
OPD-20 & 17 & $0-18$ & 9.1 & ACCCGGTCAC \\
\hline
\end{tabular}

El cebador OPD-15 consistentemente amplificó una banda en los cuatro genotipos Xanthosoma cultivados y dos silvestres (Xa-S1 y Xa-S2). Ejemplos del patrón de bandas y los tipos de polimorfismo generado se presentan en la Figura 1.
Los cebadores OPD-13 (Figura 1, a) reconocieron y amplificaron diferentes sitios en el ADN de las genotipos evaluados, exceptuando AL-C2 (pocillo 7 en el gel de agarosa). Varias bandas generadas fueron comunes solo para los genotipos y especies Xanthosoma (pocillos 4, $10,11,12,13$ y 14), otras eran comunes para la mayoría de genotipos, y otras solo eran compartidas por un 


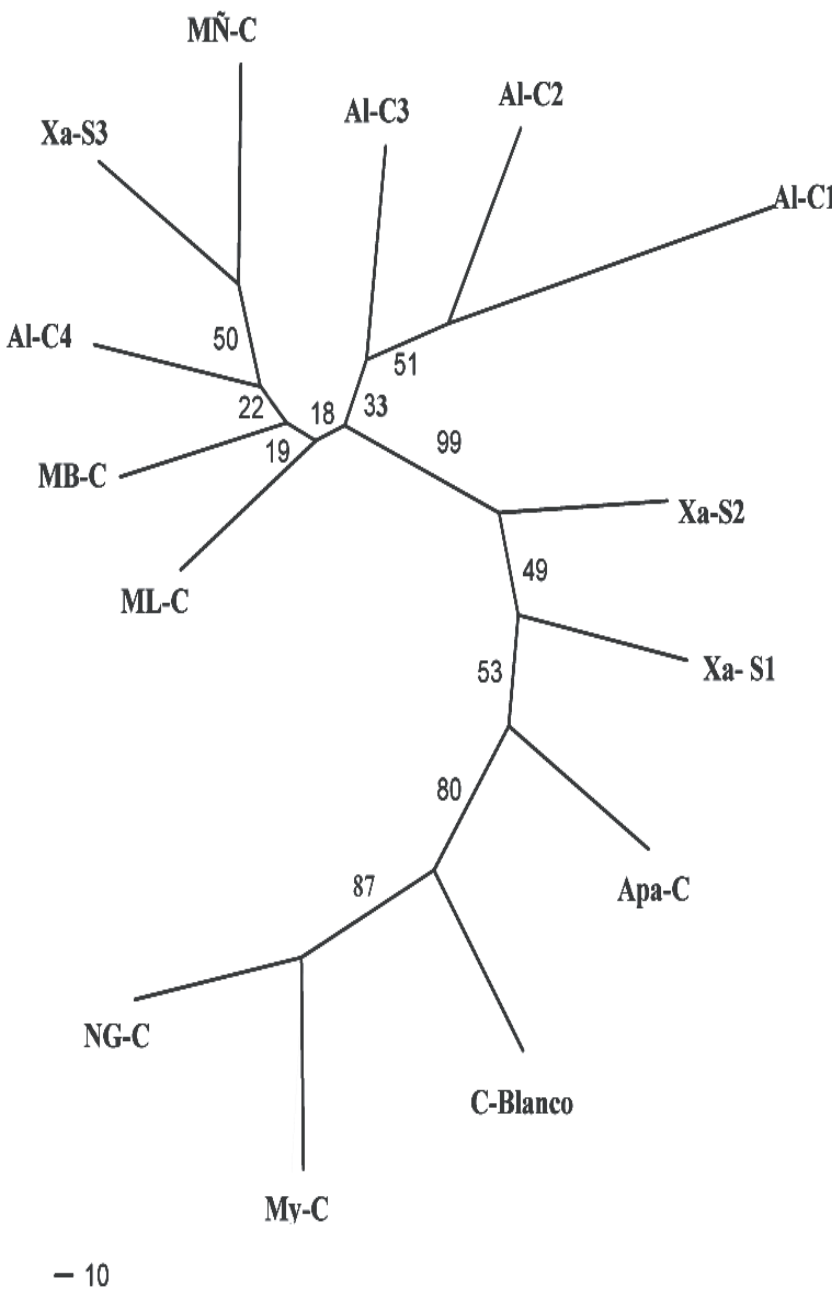

Figura 2. Análisis de los marcadores moleculares RAPD. La escala numérica indica la similitud genética. Los códigos de las accesiones corresponden con la Tabla 1.

pequeño grupo de genotipos. Los cebadores OPD-15 sólo reconocieron y amplificaron un sitio en la cadena de ADN de las especies Xanthosoma (pocillos 4, 10, 11, 12, 13 y 14), (Figura 1, b).

El análisis de los datos generados por los marcadores RAPD conglomeró claramente las cuatro especies cultivadas y las dos silvestres (Xa-S1 y Xa-S2) del género Xanthosoma en un grupo en la figura 2.X. mexicanum junto a las Colocasia y Alocasia no formaron grupos que se definan claramente (Figura 2).

La caracterización de especies Xanthosoma utilizando descriptores morfológicos ha sido reportada por Tambong et al. (1997) y Milian et al. (2003). Sin embargo a pesar de su importancia, Arús et al. (2001) asocia la caracterización morfológica a varios inconvenientes: hay que esperar que la planta llegue a su estado adulto para ver su fenotipo, el número limitado de marcadores, los efectos deletéreos y los fenotipos indeseables asociados con algunos marcadores, generalmente son de expresión dominante, frecuentemente enmascarados por efectos epistáticos e influencias ambientales.

Los marcadores moleculares del tipo RAPD han sido probados por su consistencia en la evaluación de colecciones de germoplasma de diferentes especies, y en estudios de estimación de relaciones genéticas. Tienen la ventaja de la simplicidad y habilidad para detectar relativamente pequeñas proporciones de variación genética. Sin embargo, se les cuestiona la baja reproducibilidad de sus bandas, la co-migración de diferentes productos amplificados y que detectan únicamente herencia dominante (Arús et al., 2001). A pesar de estos inconvenientes los marcadores moleculares tipo RAPD tienen potencial de generar gran número de marcadores con relativa facilidad.

En el presente estudio se evaluó la habilidad de 40 cebadores RAPD en detectar y amplificar fragmentos de la cadena de ADN de las muestras, y que además, los productos de la amplificación mostraran polimorfismo. Catorce de los 40 cebadores amplificaron fragmentos de ADN, pero solo 13 de ellos produjeron bandas polimórficas en diferentes cantidades y facilitaron la diferenciación de las especies de Xanthosoma de las especies de los otras Aráceaes. Por ser Alocasia y Colocasia géneros originarios de África y Asia, se preveía menor parentesco genético de ambos géneros con Xanthosoma, como efectivamente ocurrió.

Los cebadores más informativos reportados en este trabajo (Tabla 2), pueden ser utilizados de manera directa en estudios de relación genética entre las accesiones del banco de germoplasma del género Xanthosoma colectado en Nicaragua. Su utilización puede ayudar a disminuir entre aquellos cultivares de quequisque que existen en el país y que son nombrados de diferentes maneras.

\section{CONCLUSIONES}

Los marcadores tipo RAPD fueron efectivos en diferenciar las especies del género Xanthosoma de las especies de Colocasia y de Alocasia. El análisis fenético agrupó las cuatro Xanthosoma cultivadas junto con otras dos especies silvestres. $X$. mexicanum y las especies Colocasia no formaron grupo.

El estudio confirma la variación genética entre las especies Xanthosoma presentes en Nicaragua y establece la línea base para futuros trabajos de caracterización molecular y utilizción de las accesiones del banco de germoplasma del género Xanthosoma en trabajos de mejoramiento genético de esta especie. 
Tabla 2. Descripción taxonómica y morfológica según especie y origen de los géneros Xanthosoma, Alocasia y Colocasia

\begin{tabular}{|c|c|c|c|c|c|c|c|c|c|}
\hline \multirow[b]{2}{*}{ Género } & \multirow[b]{2}{*}{ Especie } & \multirow[b]{2}{*}{ Código } & \multirow[b]{2}{*}{ Nombre } & \multirow[b]{2}{*}{ Origen } & \multicolumn{5}{|c|}{ Descriptores morfológicos } \\
\hline & & & & & $\begin{array}{l}\text { Color } \\
\text { de } \\
\text { pecíolo }\end{array}$ & $\begin{array}{l}\text { Orientación } \\
\text { de la hoja }\end{array}$ & Pubescencia & $\begin{array}{l}\text { Brillo } \\
\text { foliar }\end{array}$ & $\begin{array}{l}\text { Color } \\
\text { de la } \\
\text { pulpa }\end{array}$ \\
\hline \multirow[t]{4}{*}{$\begin{array}{l}\text { Xanthosoma } \\
\text { Cultivadas }\end{array}$} & & My-C* & Masaya & Nicaragua & Verde & Hacia abajo & No & No I & Lila \\
\hline & $\begin{array}{l}\text { violaceum } \\
X .\end{array}$ & NG-C & Nueva & Costa Rica & Verde & “ & “ & “ & Rojizo \\
\hline & $\begin{array}{l}\text { violaceum } \\
X .\end{array}$ & Apa-C & $\begin{array}{l}\text { Guinea } \\
\text { Apali }\end{array}$ & Panamá & Verde & “ & “ & “ & “ \\
\hline & $\begin{array}{l}\text { violaceum } \\
\text { sagittifolium }\end{array}$ & Bco-C & Blanco & Costa Rica & $\begin{array}{l}\text { Verde } \\
\text { claro }\end{array}$ & “ & “ & “ & Blanco \\
\hline \multirow[t]{3}{*}{ Silvestres } & $X$. spp. & $\mathrm{Xa}-\mathrm{S} 1 *$ & - & Nicaragua & Verde & “ & “ & “ & “ \\
\hline & $X$. spp. & $\mathrm{Xa}-\mathrm{S} 2$ & - & Nicaragua & $\begin{array}{l}\text { claro } \\
\text { Verde }\end{array}$ & “ & “ & “ & “ \\
\hline & $\begin{array}{l}X . \\
\text { mexicanum }\end{array}$ & $\mathrm{Xa}-\mathrm{S} 3$ & - & Nicaragua & claro & “ & Densa & No & Yellow \\
\hline \multirow[t]{4}{*}{ Cultivadas } & A. spp & $\mathrm{Al}-\mathrm{C} 1$ & - & Desconocido & Verde & Hacia arriba & “ & $\mathrm{Si}$ & Blanco \\
\hline & A. spp & $\mathrm{Al}-\mathrm{C} 2$ & - & “ & Púrpura & “ & “ & $\mathrm{Si}$ & “ \\
\hline & A. spp & $\mathrm{Al}-\mathrm{C} 3$ & - & “ & Verde & “ & “ & $\mathrm{Si}$ & “ \\
\hline & A. spp & $\mathrm{Al}-\mathrm{C} 4$ & - & “" & $\begin{array}{l}\mathrm{V}+ \\
\text { puntos } \\
\text { lilas }\end{array}$ & $\begin{array}{l}\text { 3- } \\
\text { dimensional }\end{array}$ & “ & $\mathrm{Si}$ & “" \\
\hline \multirow[t]{3}{*}{ Cultivadas } & $\begin{array}{l}\text { C. } \\
\text { esculenta }\end{array}$ & MB-C & $\begin{array}{l}\text { Malanga } \\
\text { Blanca }\end{array}$ & “" & Verde & Hacia abajo & “ & No & Blanco \\
\hline & C. esculenta & ML-C & $\begin{array}{l}\text { Malanga } \\
\text { Lila }\end{array}$ & “" & Verde & “ & “ & No & $\begin{array}{l}\mathrm{B}+ \\
\text { puntos } \\
\text { lilas }\end{array}$ \\
\hline & $\begin{array}{l}\text { C. e. } \\
\text { antiquorum }\end{array}$ & MÑ-C & Nampí & “" & Verde & “ & $"$ & No & Blanco \\
\hline
\end{tabular}

$* \mathrm{C}=$ cultivadas; $\mathrm{S}=$ silvestres

\section{REFERENCIAS BIBLIOGRÁFICAS}

Arús, P; Cubero, Ji; García, J; Rallo, L. 2001. Marcadores moleculares en genética y mejora de plantas. En: Introducción a la Biotecnología Vegetal: métodos y aplicaciones. Caballero, Valpuesta y Muñoz Ed.

Bown, D. 2000. Aroids. Plants of the Arum Family. Second Edition. Timber Press. 392 p.

Garcia, C. 2007. Colecta y establecimiento de banco de germoplasma en colección viva e in vitro del género Xanthosoma en Nicaragua. Tesis de grado. Universidad Nacional Agraria. 62 p.

Mayo, SJ; Bogner, J; Boyce, PC. 1997. The genera of Araceae. London, Royal Botanic Graden, Kew.

Milián, M; Xiqués, X; Román, M; González, C; Sánchez, I; Nadal, M; Beovides Guerra; Guerra, D. 2003. Caracterización de la variabilidad del género Xanthosoma en Cuba, con el uso de descriptores morfoagronómicos, citogenéticos e isoenzimáticos. $61 \mathrm{p}$.

Reyes, G; Ramsell, J; Nyman, M; Kvarnheden, A. 2009. Sequence characterization of Dasheen mosaic virus isolates from cocoyam in Nicaragua. Archives of Virology.154:159-162. DOI 10.1007/s00705-008-0257-9.

Tambong, Jt; Ndzana, X; Wutoh, Jg; Dadson, R. 1997. Variability and germplasm loss in the Cameroon national collection of cocoyam (Xanthosoma sagittifolium Schott (L.). Plant Genetic Resources Newletters, No. 112:49-54.

Williams J, GK; Kubelik, AR; Livak, KJ; Rafalski, JA; Tingey, SV. 1990. DNA polymorphism amplified by arbitrary primers are usefull as genetic markers. Nucleic Acids Research, Vol 18, No 22: 6531-6535. 